\title{
FAKTOR-FAKTOR PENGARUH TERHADAP PRAKTEK KAWIN PINTAS DI KEVIKEPAN ENDE
}

\author{
Yohanes Fransiskus Siku Jata ${ }^{1}$, Frederikus Dhedhu ${ }^{2}$, Alex Reba ${ }^{3}$,Fransiskus Z.M Deidhae ${ }^{4}$ \\ Sekolah Tinggi Pastoral Atma Reksa Ende \\ Email:fransjata@stiparende.ac.id, frederikusdhedhu@stiparende.ac.id,alessandro@stiparende.ac.id, \\ ferydeidhae@stiparende.ac.id
}

\begin{abstract}
Abstrak
Penelitian ini merupakan penelitian kualitatif yang bersifat eksplanatoris. Subyek penelitian adalah 20 pasangan kawin pintas dan 7 narasumber. Penelitian ini bertujuan untuk mengetahui faktor-faktor apa saja yang mempengaruhi praktek kawin pintas (hidup bersama sebelum perkawinan mereka diresmikan dalam Gereja Katolik) dan apa karakteristik kawin pintas yang dipraktekkan di wilayah Kevikepan Ende. Hasil penelitian menunjukkan bahwa kawin pintas secara implisit direstui adat demi mempermudah proses pembelisan. Kawin pintas dipandang sebagai strategi dari pasutri untuk mempermudah urusan belis. Adanya krisis pada lembaga adat dan lembaga penegak norma (gereja dan pemerintah). Kawin pintas biasanya disertai praktek hubungan intim sebagai suami istri. Hubungan intim kadang terjadi sebelum kawin pintas sebagai bentuk pemaksaan terhadap perempuan untuk menyerahkan diri kepada laki-laki atau sebaliknya supaya laki-laki harus menerima sang perempuan agar tidak memicu konflik dengan keluarga besar perempuan. Kawin pintas merupakan ungkapan kebebasan calon suami istri. Pada masa sekarang, jodoh ditentukan oleh individu bersangkutan. Pihak keluarga hanya menerima (karena anak memiliki otonomi untuk menentukan pilihan). Praktek ini semakin umum dan ini menjadi trend atau model perkawinan zaman kini. Karena semua orang kawin pintas maka mereka juga ikut pintas. Kawin pintas terjadi karena pacaran yang singkat lewat hand phone atau mungkin dipengaruhi oleh teknologi komunikasi modern yang juga menyelubungkan pornografi.
\end{abstract}

Kata Kunci: faktor-faktor pengaruh; kawin pintas

\section{Pendahuluan}

Konsili Vatikan II menegaskan bahwa perkawinan adalah "persekutuan hidup dan kasih suami-istri yang mesra, yang diadakan oleh Sang Pencipta dan dikukuhkan dengan hukum-hukumnya, dibangun oleh janji pernikahan atau persetujuan pribadi yang tak dapat ditarik kembali" (Konsili Vatikan II: Gaudium et Spes No.48). Jadi hakikat perkawinan menurut Konsili (Gaudium et Spes 48) adalah persekutuan (komunitas) hidup dan kasih suami istri (communitas vitae et amoris intimae) yang dibentuk oleh Tuhan sendiri, yang dibangun atas dasar perjanjian antara mereka berdua, dan yang bersifat tetap (tak dapat ditarik kembali atau tak terbatalkan).

Gaudium et Spes 48 juga menggarisbawahi bahwa membangun hidup berkeluarga mempunyai kaitan erat dengan peristiwa perkawinan. Keluarga kristen baru akan berdiri kalau telah ada peristiwa perkawinan. Dengan itu mau ditegaskan bahwa tidak ada keluarga tanpa perkawinan, dan hanya ada keluarga karena perkawinan. Perkawinan adalah pintu gerbang menuju hidup berkeluarga.

Anjuran Apostolik Familiaris Consortio dikeluarkan oleh Paus Yohanes Paulus II pada tanggal 22 November 1981. Tema anjuran apostolik ini ialah Peranan Keluarga Kristen Dalam Dunia Moderen. Hakikat perkawinan menurut Familiaris Consortio dapat dijelaskan melalui tiga hal berikut: pernikahan adalah perjanjian cinta kasih antara suami dan istri yang dipilih secara bebas dan sadar; perjanjian nikah yang diadakan antara pria dan wanita merupakan ungkapan yang penuh makna dari elemen fundamental dalam pewahyuan dan pengalaman iman Bangsa Israel, yakni persekutuan cinta kasih antara Allah dan umat-Nya; dan perkawinan adalah lambang yang nyata bagi peristiwa penyelamatan (Yohanes Paulus II, 2005: 23-27).

Hasil survey yang dilakukan melalui kegiatan Katekese Umat sebagai bahan Musyawarah Pastoral VII Keuskupan Agung Ende (MUSPAS VII KAE) Tahun 2015 menunjukkan bahwa tidak kurang dari 
10.000 pasang suami istri telah menjalani hidup bersama sebelum perkawinan mereka diberkati dalam Gereja Katolik. Mereka tinggal bersama dalam satu rumah dan telah melakukan hubungan seksual layaknya suami istri dan bermaksud untuk membangun hidup berkeluarga yang sungguh dan tetap. Karena praktek hidup bersama itu, mereka pun telah memiliki anak-anak yang lahir dari hubungan yang mereka bangun tersebut. Situasi ini terjadi di hampir semua paroki yang tersebar di wilayah Keuskupan Agung Ende (dengan jumlah angka kawin pintas yang bervariasi).

Praktek hidup bersama sebelum menikah ini disebut "Kawin Pintas". Term kawin pintas ini sebenarnya dicetuskan dalam Musyawarah Pastoral Keuskupan Agung Ende (semacam sinode keuskupan) yang pertama pada tahun 1987. Yang dimaksudkan dengan kawin pintas ialah pasangan nikah yang sudah hidup bersama sebagai suami istri sebelum menikah resmi di gereja.

Gereja Katolik mengajarkan bahwa perkawinan dikatakan sah, salah satu syaratnya adalah perkawinan harus dilaksanakan melalui tata peneguhan kanonik. Yang dimaksudkan dengan perkawinan harus dilakukan melalui tata peneguhan kanonik ialah bahwa perkawinan itu harus dihadiri oleh pria dan wanita (kedua mempelai) yang saling mengucapkan pernyataan janji setia mereka (konsensus), dilaksanakan di hadapan imam yang meneguhkan perkawinan mereka serta di hadapan dua orang saksi (Kitab Hukum Kanonik 1983, 2006: Kan. 1108).

Menurut pandangan Gereja Katolik, praktek Kawin Pintas (hidup bersama sebelum perkawinan diresmikan menutut tata peneguhan kanonik) bertentangan dengan ajaran Gereja Katolik, karena:

Pertama: Praktek hidup yang dijalani oleh para suami istri itu dilakukan di luar tata tertib dan tata cara Gereja Katolik yang sah (tidak melalui tata peneguhan kanonik). Kedua: Praktek Kawin Pintas bertentangan dengan ajaran moral seksualitas perkawinan Katolik. Gereja mengajarkan bahwa orang yang berhak melakukan hubungan seksual (hubungan badan) adalah orang yang perkawinannya telah disahkan (diberkati). Yang terjadi pada praktek Kawin Pintas ialah orang belum melakukan perkawinan yang sah, tetapi mereka sudah melakukan hubungan badan layaknya suami istri.

Pandangan Gereja ini berakar pada ajaran Konsili sendiri. Konsili Vatikan II (Gaudium et Spes No. 48) berbicara tentang kesucian hidup perkawinan dan keluarga. Konsili menegaskan bahwa keluarga terbentuk melalui perkawinan. Tidak ada keluarga tanpa perkawinan, dan hanya ada keluarga karena perkawinan. Dengan ini Gereja menegaskan bahwa keluarga-keluarga katolik hanya lahir melalui peristiwa perkawinan. Peristiwa perkawinan adalah saat yang sah di mana keluarga katolik itu lahir.

Dalam beberapa Musyawarah Pastoral Keuskupan Agung Ende, persoalan kawin pintas dibahas secara mendalam untuk menentukan tindakan pastoral yang efektif. Musyawarah pastoral kedua yang diadakan pada tahun 1989, menyimpulkan bahwa belis yang mahal menjadi alasan utama untuk kawin pintas (Riwu, 1990: 212). Namun dalam musyawarah pastoral ketiga, yang diadakan pada tahun 1994, beberapa peserta kembali mempertanyakan keakuratan kesimpulan terdahulu ini, karena pada dekade sebelumnya, ketika belis bagi pengantin perempuan amat tinggi, kawin pintas justru jarang terjadi. Sebaliknya, pada tahun 1990-an, ketika belis bagi pengantin perempuan semakin berkurang, kejadian kawin pintas malah semakin marak dan meningkat secara dramatis. Pertanyaan ini juga membenarkan masyarakat matrilineal Ngada yang secara praktis tidak membayar belis namun memiliki angka kawin pintas yang tinggi. Tampaknya kemudian alasan utama untuk hidup bersama bukanlah belis bagi pengantin perempuan melainkan sejumlah faktor lainnya (Muspas III KAE, 1994: 257-258). Dalam kenyataannya, pemenuhan kewajiban membayar belis mungkin membuat pernikahan lebih sulit diatur di tempat pertama namun tidak menyebabkan pasangan tersebut tinggal bersama.

Berdasarkan temuan-temuan di atas maka ditelusuri lebih lanjut faktor pengaruh terhadap kawin pintas. Karena itu para peneliti merasa tertarik untuk melakukan penelitian dengan rumusan masalahnya: "Apa saja faktor-faktor yang memengaruhi calon pasangan suami istri mempraktekkan kawin pintas (hidup bersama sebelum perkawinan mereka diresmikan gereja)?" Adapun tujuan penelitian ini adalah: pertama, untuk mengetahui faktor-faktor yang memengaruhi calon pasangan suami istri mempraktekkan kawin pintas (hidup bersama sebelum perkawinan mereka diresmikan dalam Gereja Katolik). Kedua, 
untuk menjelaskan karakter demografis pasangan kawin pintas (usia, pendidikan, status ekonomi, proses, lama kawin pintas, jumlah anak). Ketiga, untuk menjelaskan pola kawin pintas yang dipraktekkan seperti proses perkenalan dan pertunanganan, proses pembelisan, norma dan sanksi di kalangan masyarakat patrilineal Lio Ende.

\section{Metode Penelitian}

Penelitian ini masuk dalam jenis penelitian kualitatif yang bersifat eksplanatoris. Dengan memfokuskan penelitian pada pasangan kawin pintas, para peneliti mengumpulkan dan menganalisis data yang menjelaskan hubungan antara kawin pintas dan berbagai faktor yang memengaruhinya. Unit analisis merupakan unit terkecil yang mengandung karakteristik penelitian. Dalam penelitian ini, yang menjadi unit analisis adalah pasangan suami istri yang pernah atau sedang mempraktekkan hidup bersama sebelum nikah gereja (peresmian gereja).

Dalam penelitian ini, pengumpulan data dilakukan melalui studi dokumentasi dan wawancara. Studi dokumen dengan menggunakan instrumen pedoman dokumentasi. Para peneliti mengumpulkan data sekunder dari kantor Balai Pusat Statistik (BPS) Kabupaten Ende dan dari Pusat Penelitian dan Pengembangan (Litbang) Keuskupan Agung Ende. Selain itu, studi ini juga menghimpun data-data sekunder tentang praktek dan tradisi perkawinan dalam kebudayaan setempat dari hasil-hasil studi terdahulu seperti dari hasil studi persiapan Muspas 1989 dan Muspas 1994, hasil penelitian dari beberapa antropolog di wilayah Lio-Ende. Wawancara dilakukan untuk mengumpulkan data dari 20 pasang Pasutri kawin pintas (yang pernah dan sedang) dan sejumlah narasumber yaitu: para tokoh adat yang berperan sebagai anggota Dewan Pastoral Paroki. Jumlah narasumber yang diwawancarai sebanyak tujuh orang.

Teknik analisis data yang digunakan adalah analisis data kualitatif. Data yang diperoleh dari hasil wawancara dan studi dokumentasi akan ditabulasi dan diklasifikasi menurut jenisnya. Data yang telah diklasifikasikan selanjutnya dianalisis dengan melihat hubungan satu sama lain dan ditemukan kesimpulan.

\section{Hasil Penelitian}

Berdasarkan studi dokumen, khususnya dokumen Muspas VII KAE tahun 2015, ditemukan jumlah umat kevikepan Ende adalah 152.850 orang (yang terdiri dari 71.632 laki-laki dan 77.948 perempuan). Ada sebanyak 35.649 pasang suami istri yang mendiami 32.505 rumah. Jumlah pasutri sebanyak 35.649 pasang. Dari jumlah itu, pasangan yang belum menikah gereja berjumlah 4.677 pasang dan yang tidak menikah gereja sebanyak 938 pasang. Dengan demikian, ada sebanyak 5.615 pasang suami istri yang hidup bersama tanpa ikatan resmi gereja. Selain itu, ada 670 pasang yang pisah ranjang, 49 pasang pasutri yang cerai sipil, dan umat yang merantau sebanyak 12.571 orang.

Data yang dikumpulkan di empat paroki di Kevikepan Ende yang dipilih secara acak mewakili wilayah etnis Lio dan sub etnis Ende serta perbedaan wilayah kota dan desa, pada tahun 2012-2017 terdapat 1321 pasang kawin pintas. Secara rinci dapat dilihat dalam tabel di bawah ini.

Tabel 1

Data pasangan yang nikah gereja dan kawin pintas dari empat paroki selama tahun 2012-2017

\begin{tabular}{|l|l|l|l|r|}
\hline No & Paroki & $\begin{array}{l}\text { Jumlah Pasutri Yg } \\
\text { Nikah Gereja }\end{array}$ & $\begin{array}{l}\text { Jumlah Yg } \\
\text { Pintas }\end{array}$ & $\begin{array}{l}\text { Persentase } \\
\text { Kawin Pintas }\end{array}$ \\
\hline 1 & Onekore & 398 & 374 & $93,96 \%$ \\
\hline 2 & Kombandaru & 387 & 383 & $98,45 \%$ \\
\hline 3 & Detusoko & 353 & 350 & $99,15 \%$ \\
\hline 4 & Wolowaru & 219 & 214 & $97,71 \%$ \\
\hline & Jumlah & 1357 & 1321 & $97,34 \%$ \\
\hline
\end{tabular}

Berdasarkan hasil wawancara dengan pasangan kawin pintas, peneliti menemukan 11 hal berikut:

Pertama, usia: Usia para pasangan nikah pintas berkisar antara 19 sampai dengan 37 tahun pada saat mulai hidup bersama. Pada umumnya suami berusia lebih tua dari istri. Di Kombandaru bahkan perbedaan usia cukup mencolok. Laki-laki pada umumnya lebih tua antara 1 sampai dengan 13 tahun. 
Beberapa pasangan istri lebih tua namun tidak terdapat perbedaan signifikan karena hanya selisih $1-3$ tahun.

Kedua, pendidikan: Pendidikan para pasangan kawin pintas berkisar dari tamatan SD sampai dengan S2. Dengan demikian, variable pendidikan tidak berpengaruh terhadap kawin pintas.

Ketiga, pekerjaan: Sektor primer seperti petani sampai dengan pedagang, satpam dan usaha wiraswasta. Di samping itu ada juga pasangan yang berprofesi sebagai tukang, sopir dan juru rawat serta guru dan bahkan ada yang dosen.

Keempat, lama berpacaran atau berkenalan: Masa kenalan atau pacaran berkisar dari 1 bulan sampai 8 tahun. Namun di sisi lain, ada yang tidak kenal satu sama lain (hanya bertemu pada saat pesta atau kenal karena tinggal sekampung, juga karena dipertemukan oleh keluarga) lalu sang wanita lari mengikuti pria.

Kelima, masa pertunanganan: Sebagian besar pasangan nikah pintas tidak ada masa pertunanganan. Satu pasang gantung baju dan satu meminang, tapi setelah itu mereka pintas.

Keenam, lama pintas: Rentang masa pintas umumnya berkisar antara 1 tahun sampai 7 tahun. Namun ada juga yang hanya 2 bulan dan yang lain ialah ada yang belum melangsungkan pernikahan mereka.

Ketujuh, proses pintas dan belis: Umumnya terjadi dengan cara perempuan lari ikut pria dan langsung tinggal di rumah pria. Model ini merupakan praktek yang umum terjadi di kalangan masyarakat Lio Ende. Perempuan yang lari ikut (menyerahkan diri ke rumah laki-laki) merupakan suatu strategi untuk mempercepat proses perkawinan. Karena itu, proses belis untuk cara yang demikian, pihak perempuan umumnya tidak akan menuntut belis dengan harga yang tinggi. Secara ekonomis, proses pembelisan setelah lari ikut biasanya lebih murah dibandingkan dengan cara melalui proses meminang atau lamaran resmi. Karena wanita "lari ikut" laki-laki maka urusan belis sering tidak dipedulikan. Proses adat masih tetap dijalankan, namun belis yang diberikan hanya sekedar ada.

Kedelapan, tempat tinggal: Hampir semua pasangan pintas tinggal di rumah orang tua suami atau keluarga suami (patrilocal). Ada yang tinggal di rumah sendiri (suami); tetapi ada juga yang tinggal di rumah orang tua istri karena alasan praktis kerja di kampung wanita. Dalam masyarakat patrilineal, perempuan atau istri harus tinggal di rumah laki-laki.

Kesembilan, proses belis: Pada umumnya sudah ada proses belis, yang sengaja dilakukan maupun yang tidak sengaja (karena kematian salah seorang anggota keluarga dekat istri). Kewajiban sosial sebagai menantu dan bukti tanggungjawab sosial (pertukaran dalam perkawinan). Ungkapan kewajiban sosial ini dinyatakan dalam bentuk barang (emas, sarung); hewan (babi, sapi) dan sejumlah uang.

Kesepuluh, jumlah anak: Pada umumnya pasangan pintas telah memiliki anak satu sampai tiga orang. Hal ini amat berhubungan dengan tujuan dari perkawinan itu sendiri yaitu untuk mendapatkan keturunan. Dalam masyarakat patrilineal Lio Ende, perkawinan yang tidak mendapatkan keturunan dianggap sebagai aib atau kutukan dan merendahkan status sang istri.

Kesebelas, persiapan berkat nikah: Hampir semua pasangan nikah pintas yang diwawancarai melanjutkan hidup bersama mereka melalui ikatan perkawinan yang sah menurut tata aturan Gereja Katolik. Karena itu, sebelum melangsungkan perkawinan, pasangan nikah pintas dan keluarganya mempersiapkan segala hal yang perlu berkaitan dengan rencana perkawinan gereja (termasuk mengikuti proses yang disebut kursus persiapan perkawinan). Proses persiapan ini membuktikan bahwa praktek kawin pintas tidak bermaksud menjadi model perkawinan coba-coba atau sejenis perkawinan kontrak. Dalam konteks Ende Lio, perkawinan kawin pintas menjadi suatu tahapan menuju perkawinan resmi dalam Gereja Katolik. Beberapa pasangan pintas yang setelah hidup bersama lalu berpisah biasanya disebabkan oleh konflik keluarga atau antar pribadi yang berlarut-larut dan tidak dapat diselesaikan.

\section{Diskusi}

Berdasarkan hasil penelitian di atas dapat didiskusikan beberapa hal berikut:

Pertama, kawin pintas tidak mendapatkan sanksi dari lembaga adat, keluarga, agama, dan negara. Apakah benar? Secara faktual agama dan negara memberikan sanksi dalam praktek hidup harian. 
Pria dan wanita yang telah melakukan praktek kawin pintas umumnya tahu bahwa kalau mereka mengikuti perayaan ekaristi, mereka tidak diperkenankan menyambut komuni kudus atau Tubuh Kristus (karena mereka sedang dalam keadaan berdosa). Jadi dalam gereja katolik, sanksi bagi umat yang telah melakukan praktek kawin pintas adalah mereka tidak boleh menerima Tubuh Kristus.

Sebagai Warga Negara Indonesia (WNI), Negara baru mengakui warganya telah berkeluarga kalau telah melaksanakan perkawinan dalam agamanya masing-masing (bdk. UU RI No.1/1974 asal 2 ayat 1). Karena itu kalau ada warga yang telah hidup bersama sebelum menikah, maka negara pun belum mengakui bahwa warganya itu telah berkeluarga. Tetapi negara tidak memberikan sanksi kepada warganya yang telah mempraktekkan hidup bersama sebelum menikah itu. Bahkan ada Aparatur Sipil Negara (ASN) yang telah hidup bersama sebelum menikah pun tidak diberi sanksi.

Dalam masyarakat adat di mana para pasangan kawin pintas berada, tidak ada aturan adat yang memberikan denda atau sanksi kepada warganya yang telah melakukan praktek kawin pintas. Keluarga tidak memberikan sanksi kepada anak-anak mereka yang telah melakukan praktek kawin pintas. Bahkan keluarga mempersiapkan proses lari ikut (di mana pihak keluarga laki-laki bersama dengan para tua adat dan kepala dusun menunggu kedatangan perempuan). Pihak perempuan pun melepaskan anak gadis mereka ke rumah laki-laki dengan restu berkumpul bersama sebelum berangkat. Jadi secara implisit, keluarga (adat) merestui praktek kawin pintas.

Situasi ini meneguhkan pikiran Giddens tentang teori strukturasi, yang menegaskan bahwa setiap norma mesti disertai dengan praksis dan penegakan terhadap norma itu. Tanpa penegakkan norma (yang menyata dalam praksis), maka norma hanya menjadi wacana. Norma yang tidak ditegakkan, tidak dipraktekkan, norma yang dilanggar akan tidak efektif (Anthony Giddens, 1992).

Kedua, adanya krisis pada lembaga adat dan lembaga penegak norma (gereja dan pemerintah). Dalam urusan perkawinan, para tua adat mulai tidak dilibatkan. Dengan itu peran mosalaki mulai hilang. Hal ini dapat mendatangkan bahaya bahwa penegakan norma adat semakin melemah. Karena urusan perkawinan hanya tergantung pada negosiasi dan penafsiran dua belah pihak, yakni pihak-pihak yang terlibat. Hal ini dapat berpengaruh juga pada belis. Norma gereja pun tidak digubris (seperti larangan menerima komuni kudus), kecuali secara publik sudah diketahui hamil atau sudah berhubungan intim di luar perkawinan resmi. Gereja tidak memberikan sanksi lain yang lebih akurat selain larangan menerima komuni.

Teori strukturasi menggambarkan otorita individu maupun institusi menjadi dasar kalkulasi tindakan. Bila tidak ada otorita maka ada kemungkinan besar terjadi pelanggaran terhadap norma.

Ketiga, kawin pintas secara implisit direstui adat demi mempermudah proses pembelisan. Kawin pintas sebagai strategi dari pasutri untuk mempermudah urusan belis, dan hal ini direstui adat (tidak ada sanksi). Belis nikah resmi dengan proses lamaran sampai dengan nikah jauh lebih mahal dibandingkan dengan pintas. Misalnya di Paroki Wolowaru: Tuntutan adat dari keluarga wanita pada saat peminangan adalah sapi 10 ekor, kerbau 10 ekor, babi 10 ekor, kuda 10 ekor, uang 75 juta. Seandainya keluarga wanita tidak menuntut belis sebesar ini maka pasangan tidak akan melakukan nikah pintas.

Dalam proses kawin pintas, pihak perempuan dianggap berada pada posisi tawar yang lemah sehingga tidak dapat menuntut belis yang tinggi (kalau perempuan lari ikut berarti laki-laki pangku kakiterm resmi). Masa pintas yang makin lama karena tuntutan belis yang makin bertambah misalnya pencatatan nikah harus dengan belis tertentu (1 ekor sapi dengan sejumlah uang) bagi paman.

Dalam etnis Lio Ende, kedua pihak suami istri mempertukarkan belis dengan nilai yang hampir seimbang. Pihak laki-laki memberikan hewan: sapi, kerbau, kuda, babi, emas, dan uang. Pihak perempuan membalas dengan simbol perempuan seperti sarung, makanan, kelengkapan rumah tangga. Belis selain menjadi pertukaran suami istri, tetapi juga menjadi ajang pertarungan status sosial. Semakin tinggi status sosial semakin tinggi juga belis. Dengan demikian, semakin tinggi status sosialnya, baik pihak laki-laki maupun perempuan, maka tawar-menawar pertukaran akan semakin mahal. Dengan kata lain, proses lari ikut dan pintas menjadi strategi agar proses pembelisan menjadi lebih murah dan gampang.

Proses pembelisan sangat ditentukan oleh kemampuan ekonomis pihak laki-laki dan perempuan serta negosiasi. Contoh, pasangan yang kondisi ekonominya baik, cenderung memberikan belis yang tinggi. 
Proses pembelisan juga amat dipengaruhi ekonomi modern. Wilayah sub etnis Ende seperti Kombandaru dan Onekore yang dekat dengan kota sudah menggunakan emas murni. Padahal dalam tradisi asli, emas yang digunakan adalah perhiasan sepuhan yang diwariskan dari zaman dahulu. Praksis sosial amat ditentukan oleh perkembangan zaman.

Keempat, kawin pintas sebagai proses menjamin kelangsungan hubungan suami istri. Ada ketakutan pada pihak perempuan bahwa mereka akan kehilangan calon suami. Apalagi sekarang pasar jodoh semakin banyak persaingan. Survey menjelang Muspas VII KAE tahun 2015 menunjukkan bahwa di Kevikepan Ende jumlah laki-laki lebih kurang daripada perempuan (Laki-laki: 71.632; Perempuan: 77.948).

Kawin pintas biasanya disertai praktek hubungan intim sebagai suami istri. Hubungan intim kadang terjadi sebelum kawin pintas sebagai bentuk pemaksaan terhadap perempuan untuk menyerahkan diri kepada laki-laki atau sebaliknya supaya laki-laki harus menerima sang perempuan agar tidak memicu konflik dengan keluarga besar perempuan (rongo tama kopo peka). Hubungan intim juga dilakukan karena adanya ketakutan akan ditinggalkan pasangan. Di sisi lain, perempuan yang sudah tidak perawan atau memiliki anak di luar pernikahan akan menjadi perempuan yang tidak laku (sulit mendapatkan jodoh). Dalam kasus perkawinan pintas, perempuan berada pada posisi tawar yang lemah, dan dalam kasus tertentu, konflik keluarga dapat membubarkan kehidupan bersama pasutri kawin pintas.

Kelima, kawin pintas merupakan ungkapan kebebasan calon suami istri. Pada zaman dahulu, jodoh ditentukan oleh keluarga atau sekurang-kurangnya direstui pihak keluarga. Pada masa sekarang, jodoh ditentukan oleh individu bersangkutan. Pihak keluarga hanya menerima (karena anak memiliki otonomi untuk menentukan pilihan). Kecuali laki-laki yang pendiam dan sulit dalam relasi, dipasangkan oleh sang bibi. Praktek ini semakin umum dan ini menjadi trend atau model perkawinan zaman kini. Karena semua orang kawin pintas maka mereka juga ikut pintas. Kawin pintas terjadi karena pacaran yang singkat lewat hand phone atau mungkin dipengaruhi oleh teknologi komunikasi modern yang juga menyelubungkan pornografi.

\section{Kesimpulan}

Berdasarkan hasil penelitian dapat disimpulkan Pertama, tidak adanya sanksi adat yang tegas terhadap pasangan kawin pintas dan keluarga justru memberikan peluang atau kemungkinan untuk terjadinya kawin pintas. Kedua, Kawin pintas secara implisit direstui adat demi mempermudah proses pembelisan. Karena itu prkatek kawin pintas bagai strategi dari pasutri untuk mempermudah urusan belis. Ketiga, kawin pintas sebagai proses menjamin kelangsungan hubungan suami istri. Ada ketakutan pada pihak perempuan bahwa mereka akan kehilangan calon suami. Keempat, kawin pintas merupakan ungkapan kebebasan calon suami istri.

\section{REFERENSI}

Dokumen Konsili Vatikan II: Edisi Bahasa Indonesia (diterjemahkan oleh R. Hardawiryana, SJ.). Jakarta: Obor, 2009.

Giddens, Anthony. 1992. "Structuration theory: past, present, and future," in Giddens Theory of Structuration. A Critical Appreciation. London: Routledge

Kitab Hukum Kanonik Tahun 1983. 2006. Jakarta: KWI

Loy Riwu, Philipus. 1990. "Pastoral Musyawarah of The Archdiocese of Ende - Indonesia". East Asian Pastoral Review. 28 (3): 200-223.

Muspas III KAE. 1993. “Pastoral perkawinan dan hidup keluarga,” In Penyalur Berita KAE. X (3): 256275.

Yohanes Paulus II. 2005. Familiaris Consortio. Jakarta: KWI

UU RI No.1 Tahun 1974 Tentang Perkawinan. 2012. Citra Umbara-Bandung 